\title{
Proposta paramétrica para projetos sustentáveis de Habitação de Interesse Social em ambiente BIM
}

\author{
Parametric proposal for development of sustainable \\ housing projects in BIM tool
}

\section{Mayra Soares de Mesquita Mororó Neliza Maria e Silva Romcy Daniel Ribeiro Cardoso José de Paula Barros Neto}

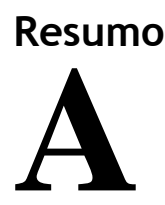

s inconstantes políticas de habitação brasileiras têm-se mostrado incapazes de oferecer moradia adequada para a população de baixarenda no Brasil ( 0 e 3 salários mínimos), tanto no que diz respeito aos aspectos quantitativos como qualitativos. As propostas habitacionais direcionadas a essa população parecem desconsiderar a complexidade que envolve a moradia no que se refere à articulação do projeto com a esfera cultural e outros aspectos da dimensão individual e familiar dos usuários. Como forma de promover uma personalização da habitação considerando os modos de morar e a sustentabilidade, este trabalho teve como objetivo desenvolver um método de projeto direcionado à Habitação de Interesse Social (HIS) associado a um ambiente virtual de projeto alimentado por parâmetros. Estes parâmetros foram coletados em habitações autoconstruídas, registrados em uma gramática da forma descritiva e posteriormente ajustados considerando os critérios de sustentabilidade do Selo Casa Azul. A pesquisa trata de um estudo qualitativo, com caráter exploratório, e a estratégia de pesquisa utilizada foi a pesquisa construtiva, dividida em três fases: compreensão, desenvolvimento e consolidação, com emprego de instrumentos metodológicos específicos para cada etapa. Como resultado foi produzido um plug-in ancorado em uma ferramenta BIM com capacidade de gerar propostas de moradias a partir da inserção de parâmetros.

Palavras-chaves: Autoconstrução. Gramática da forma. Sustentabilidade. Parametrização. HIS. BIM.

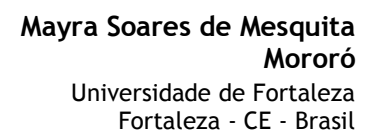

Neliza Maria e Silva Rimcy Universidade Federal do Ceará Fortaleza - CE - Brasil

Daniel Ribeiro Cardoso Universidade Federal do Ceará Fortaleza - CE - Brasil

José de Paula Barros Neto Universidade Federal do Ceará Fortaleza - CE - Brasil

Recebido em 15/04/16 Aceito em 26/07/16

\begin{abstract}
Unstable Brazilian housing policies have been unable to provide adequate housing for the low-income population in Brazil (0 to 3 minimum wages), considering both quantitative and qualitative aspects. The housing proposals designed for this population seems to ignore the complexity involved housing when it comes to the cultural, individual and family aspects of users. As a way of promoting housing customization considering living habits and sustainability, this study aimed to develop a design method for social housing, associated with a virtual environment powered by design parameters. These parameters were collected from selfconstructed dwellings, registered in a shape grammar and adjusted after considering "Blue House Seal”" sustainability criteria. This research project is a qualitative and exploratory study, based on the Constructive Research approach. The work was divided into three stages: understanding, development and consolidation, with specific methodological tools for each step. The result is a plug-in, based on a BIM tool, for generating proposals for social housing, considering the parameters previously collected and adjusted.
\end{abstract}

Keywords: Self-construction. Shape grammars. Sustainability. Parameterization. Housing. BIM. 


\section{Introdução}

Ao longo do século passado, principalmente a partir da década de 40, o Brasil tem experimentado um acelerado processo de urbanização e um aumento extraordinário de sua população urbana, resultado dos processos de modernização e da difusão da cidade como símbolo do progresso (MARICATO, 2003). Tais dinâmicas, associadas a uma restrita produção habitacional do mercado imobiliário e a políticas públicas ineficientes, têm gerado a inacessibilidade de parte da população à moradia adequada e levado a uma massiva concentração do déficit habitacional entre as famílias de baixa renda (MARICATO, 2001).

O quadro atual de déficit de moradias é ainda resultado de uma série de políticas habitacionais desenvolvidas desde o século passado, acompanhando a realidade político-econômica do país em diversas fases. Bonduki (2004) e Taschner (1997) apresentam uma análise da trajetória da política habitacional brasileira, deixando evidente sua característica mais marcante: a contínua transferência de responsabilidade do Estado para a sociedade.

Em 2009, com a crise econômica que se instalava no cenário internacional, o governo institui o programa Minha Casa Minha Vida (MCMV), que, para além da redução do déficit habitacional, tinha a finalidade de movimentar a economia e afastar a crise do país. O modelo do programa governamental, operacionalizado pelo setor privado, direciona seus recursos para a redução dos problemas quantitativos de acesso a moradia, e, para tanto, exige a redução dos custos de implantação dos empreendimentos.

Uma conhecida estratégia para a redução dos custos, vivenciada historicamente com a experiência do Banco Nacional da Habitação (BNH), é a adoção de soluções padronizadas de projeto para as unidades habitacionais, muito embora também já se tenha um relevante aprendizado sobre os malefícios dessa prática, dentre as quais: discordância com a realidade socioeconômica, desconsideração dos condicionantes físico-ambientais e impessoalidade da habitação, que se reflete em conflitos usuárioambiente, aumentando o desejo de o morador modificar sua casa (MARROQUIM, 2007).

No atual contexto do programa MCMV, percebese que grande parte da produção de moradia tem se mostrado inadequada aos usos demandados, sobretudo por desconsiderar a complexidade que envolve a habitação no que se refere à articulação do projeto com a esfera cultural e outros aspectos da dimensão individual e familiar dos usuários.
Em Fortaleza, por exemplo, Pequeno e Rosa (2016) evidenciaram uma produção segregada espacialmente, com baixa diversidade tipológica e pouca flexibilidade projetual.

Diante desse cenário, a personalização da habitação de interesse social é um tema que merece atenção. Conforme justifica Duarte (2007), a satisfação do usuário é o indicativo de qualidade das edificações, portanto um alto nível de personalização tende a aumentar o grau de satisfação do morador, evitando reformas após a ocupação; e o conhecimento sobre o modo de morar das famílias a serem atendidas nos programas pode revelar a forma mais adequada de organizar sua moradia.

Ferreira (2012, p. 87) ressalta que:

Geralmente, as soluções autóctones, que representam a cultura local, como casas caiçaras, casas caipiras, são indicativas das melhores soluções para a região, pois incorporam o saber local e suas tradições.

A análise tipológica, geralmente restrita ao campo da história da arquitetura, pode ser empregada no estudo do vernacular e estar subsidiando uma "[...] reflexão crítica preliminar sobre o próprio projeto [...]", servir de guia durante todo o processo, a fim de produzir soluções variadas que respondem a determinadas exigências do contexto em que se insere (MORAES, 2010, p. 25).

Tipo não se caracteriza pela imposição de um programa ou projeto por alguém, trata-se de uma forma de design, de algo que emerge do vernacular a partir de uma produção coletiva, de um conhecimento herdado e cultivado que encontra variações em cada habitação (CARDOSO, 2011).

Considerável percentual da população brasileira tem sido conduzida a alternativas informais de acesso a terra, sob a forma de ocupação e autoconstrução de suas casas, visto que o conjunto de políticas habitacionais não tem conseguido atender às demandas sociais em termos quantitativos nem qualitativos (MARICATO, 2001). Acredita-se que a realização de estudos sobre a produção autônoma da moradia poderá contribuir para a composição de quadro de informações voltadas para amplo universo tipológico de habitação de interesse social.

Estudos como o de Duarte (2007), sobre a personalização da habitação e sua formalização em gramática da forma, indicam a viabilidade da metodologia com a inserção de dados em sistemas que permitem potencializar a produção habitacional de forma a fornecer produtos que 
atendam aos anseios da população, sobretudo para famílias envolvidas em programas de urbanização de favelas com reassentamento. Gramática da forma, ou shape grammar, consiste em um sistema de geração gráfico criado na década de 70 por George Stiny e James Gips, que apresenta grande potencialidade tanto na análise de edifícios existentes quanto na geração de novos objetos arquitetônicos.

Em consonância com a temática, a importância do uso de ferramentas computacionais no processo de projeto de arquitetura vem demonstrando seu potencial na proposição de soluções arquitetônicas, simulações ambientais e gerenciamento da informação.

Nesse contexto, o Building Information Modeling (BIM) destaca-se como a criação e uso de informação computacional coordenada e consistente sobre o projeto de uma edificação informação paramétrica usada para tomada de decisões em projeto, produção de documentação, previsão do desempenho da edificação, estimativa de custo e planejamento de obra (KRYGIEL; NIES, 2008).

O uso da parametrização surge como uma estratégia de personalização de projetos, por alcançar uma ampla variedade de soluções ao sistematizar os requisitos dos usuários e auxiliar a tomada de decisão diante dos problemas de projeto. Dessa forma, incentiva-se o estudo dos diferentes domínios de conhecimento na indústria da Arquitetura, Engenharia e Construção (AEC), visando à formalização de parâmetros e a alimentação de sistemas de apoio à tomada de decisão ao projeto que utilizem ferramentas computacionais como o BIM.

A inserção dessas novas tecnologias apresenta potencial para a introdução de melhorias habitacionais que envolvam flexibilização, personalização e modulação, além da redução do desperdício de materiais, e o gerenciamento das informações durante o ciclo de vida da edificação. Fica claro, portanto, seu potencial de aplicação na proposição de projetos de Habitação de Interesse Social (HIS).

Nesse contexto, o objetivo do presente artigo consiste no desenvolvimento de um método de projeto de HIS associado a um ambiente virtual alimentado por parâmetros. Tal método parte da análise e síntese de unidades habitacionais autoconstruídas como forma de definir um sistema de conhecimento sobre o usuário que, alinhado aos critérios de sustentabilidade do Selo Casa Azul, é traduzido em parâmetros de projeto. Dessa forma, a pesquisa visa a contribuir com a utilização de tecnologias da informação para pensar novos modos de projetar e produzir habitação para a população de baixa renda.

\section{Referencial teórico}

A modelagem paramétrica consiste na representação computacional de um objeto construído com entidades, cujos atributos podem ser fixos ou variáveis. Os atributos fixos são denominados como controlados e os atributos variáveis podem ser representados por parâmetros e regras, de forma a permitir que objetos sejam automaticamente ajustados de acordo com o controle do usuário e a mudança de contexto (ANDRADE; RUSCHEL, 2009).

Dessa forma, é possível representar os componentes da edificação por parâmetros e regras que determinam tanto sua geometria quanto as propriedades e as características não geométricas. Os elementos de representação passam a ser objetos associados entre si e a informações adicionais que os caracterizam, como dimensões, materiais e quantitativos - denominadas parâmetros.

O objetivo do BIM é gerar um modelo da edificação, por meio do qual uma realidade futura pode ser simulada, contendo informações relevantes, relativas ao projeto e aos processos, o que permite maior controle sobre o empreendimento e a integração entre seus diferentes agentes. $\mathrm{O}$ enriquecimento desse modelo com todos os tipos de informação permite um banco de dados capaz de tornar os processos de gerenciamento melhores e mais consistentes, mesmo após a execução da edificação.

Segundo Mitchell (2004), o projeto assistido por computador e a tecnologia de fabricação permitem a redução de tempo e custo em edificações com grande porte e alta complexidade. $\mathrm{O}$ projeto paramétrico e a automação de funções apontam para um futuro que contemple a fabricação digital, a customização e a personalização. A procura de uma solução única e universal, base da Revolução Industrial e do Movimento Moderno, é substituída pela multiplicidade e pela particularidade (ORCIUOLI, 2010).

Desde 1980, ferramentas convencionais de projeto são baseadas em conceitos genéricos de copiar, cortar e colar, combinados em ações de adicionar, apagar e reposicionar elementos. Tais ações funcionam no projeto convencional porque as partes são manipuladas de maneira independente. Por outro lado, sistemas paramétricos garantem o estabelecimento de relações através das quais as partes do projeto se mantém conectadas, garantindo a consistência do todo. Assim, amplia- 
se a capacidade do projetista de explorar ideias por meio da redução de retrabalho, além de agilizar a geração de variações de um mesmo modelo com alternativas de soluções diversas (WOODBURY, 2010).

Nesse contexto, insere-se, ainda, o formalismo conhecido como gramática da forma (shape grammar), que, apesar de visar inicialmente a um sistema de geração de formas para a pintura e a escultura, logo foi percebida com potencial para o estudo de linguagens arquitetônicas e geração de diversos indivíduos com semelhanças entre si. Segundo Celani et al. (2007), gramática da forma é definida pelos seguintes elementos:

(a) vocabulário de formas: conjunto finito de formas primitivas que farão parte da gramática;

(b) relações espaciais: combinações espaciais desejadas entre as formas primitivas do vocabulário;

(c) regras: a partir das relações espaciais são definidas regras de transformação do tipo $\mathrm{AB}$ (ao encontrar A, substitua por B). Essas regras podem acrescentar novos elementos (aditiva) ou retirar elementos existentes (subtrativas); e

(d) forma inicial: para dar início à aplicação das regras, é necessário selecionar uma forma inicial, pertencente ao vocabulário de formas.

O reconhecimento ou a criação de uma gramática da forma para posterior aplicação em modelos paramétricos surgem como possibilidade para a geração automática de diversos indivíduos semelhantes (tipos), estratégia interessante para a customização em massa.

Dessa forma é possível observar como a formalização de parâmetros inseridos no ambiente BIM pode trazer novas possibilidades à customização em massa, principalmente quando associada a estratégias de entrada e saída de dados, além de reconhecimento e criação de regras através de referências anteriores de projeto.

\section{Método de pesquisa}

Os procedimentos empregados foram distribuídos em quatro etapas: 1. Estudo de caso; 2. Gramática da forma das habitações; 3. Parametrização dos dados; 4. Aplicação (plug-in). Em cada etapa foram utilizados instrumentos e métodos diferentes, os quais serão descritos a seguir.

\section{Estudo de caso}

A pesquisa teve início com a realização de um estudo de caso aplicado em uma área de ocupação consolidada, definida como Zonas Especiais de Interesse Social (ZEIS) no Plano Diretor Participativo do Município de Fortaleza (PDPFOR), de onde foi selecionada uma amostra de unidades habitacionais autoconstruídas para a coleta de dados. Essa coleta foi realizada em três etapas, e aplicada a partir de um arranjo metodológico que incluiu: leitura espacial, formulários, levantamento físico das unidades e entrevistas narrativas com os moradores, conforme o Quadro 1.

O material obtido constitui-se de anotações, fotografias, desenhos das plantas baixas de 94 unidades habitacionais e de áudios e formulários referentes às entrevistas com os moradores.

\section{Gramática da forma}

Nas análises do material coletado, buscou-se por elementos recorrentes que se apresentam constantes na maioria das unidades, de forma a caracterizar um tipo. As tipologias encontradas, assim como o processo de formação das unidades, foram registradas em uma gramática da forma descritiva.

Figura 1 - Fluxo metodológico

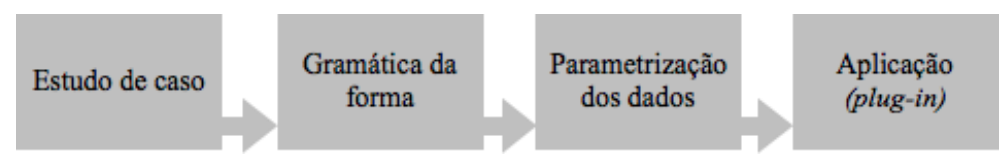

Quadro 1 - Procedimentos investigativos

\begin{tabular}{|c|l|l|}
\hline ETAPAS & PROCEDIMENTOS DE COLETA & \multicolumn{1}{c|}{ PROCEDIMENTOS DE REGISTRO } \\
\hline \multirow{2}{*}{} & Leitura espacial & $\begin{array}{l}\text { Fichas de caracterização, fotografias, croquis, } \\
\text { anotações }\end{array}$ \\
\hline \multirow{2}{*}{} & Formulário e/ou levantamento de dados & Ficha de anotações \\
\cline { 2 - 3 } & Levantamento físico das unidades & Registro gráfico (croquis) e fotográfico \\
\hline \multirow{3}{*}{} & Entrevista narrativa & $\begin{array}{l}\text { Gravação de áudio } \\
\text { Desenho da unidade }\end{array}$ \\
\hline
\end{tabular}

30 Mororó, M. S. de M.; Romcy, N. M. e S.; Cardoso, D. R.; Barros Neto, J. de P. 
Tal gramática foi traduzida em parâmetros, a fim de alimentar um sistema computacional de projetos pertencentes a uma mesma tipologia, no entanto alguns desses parâmetros divergem dos determinados nos meios legais, sendo necessário adequá-los para torná-los viáveis de aplicação. Para tanto, foram realizadas consultas às normas vigentes para projetos de HIS e às diretrizes do Selo Casa Azul, a fim de calibrar também os aspectos construtivos e de conforto ambiental.

\section{Parametrização}

A terceira etapa da pesquisa consiste na parametrização dos dados a serem inseridos no software BIM. Para a realização desta etapa adotou-se a estratégia da pesquisa construtiva (constructive research). A investigação parte da definição de um problema com relevância prática e teórica, seguida da compreensão do tema e desenvolvimento de uma construção para resolver o problema. Por fim, a implementação da solução possibilita descobertas práticas e reflexões teóricas (LUKKA, 2003).

Considerando o objetivo da pesquisa, adotou-se como construção o desenvolvimento de um plug-in em software BIM voltado para a customização de projetos de HIS, considerando os parâmetros estabelecidos a partir das habitações autoconstruídas e os requisitos de sustentabilidade. Assim, antes da etapa de programação, foi necessário sistematizar o fluxo de informações parametrizadas que descreveriam o processo de elaboração do projeto, com seus respectivos dados de entrada (input) e saída (output).

A definição dos requisitos de sustentabilidade ambiental partiu dos manuais de certificação ambiental, por sua importância na inserção das questões de sustentabilidade em projetos, além da facilidade de compreensão pela forma de avaliação no formato de checklists. Dentre as certificações existentes optou-se por utilizar o Selo Casa Azul por tratar-se de uma certificação voltada não somente para o contexto das habitações de interesse social, mas também para a realidade brasileira.

Para a sustentabilidade social, foram utilizadas as características sistematizadas a partir das etapas anteriores (coleta de dados e gramática da forma), que buscaram compreender a real necessidade dos usuários e seus hábitos, a partir do caso aplicado na comunidade.

O cruzamento e a análise dos dados socioambientais citados resultaram na definição de um fluxo de informações com oito etapas consecutivas para a elaboração de projetos sustentáveis de HIS na realidade da cidade de Fortaleza.

\section{Aplicação (plug-in)}

Para a implementação do plug-in em aplicativo BIM, foi selecionado o software ArchiCAD (Graphisoft), devido à disponibilidade de versão para fins acadêmicos (educacional) e à experiência anterior da equipe de pesquisadores. O estabelecimento de uma interface direta com o aplicativo original foi realizado por meio do Graphisoft API (Graphisoft Application Programming Interface Development Kit), que consiste em um conjunto de bibliotecas de vínculos para programação em $\mathrm{C}++$, oferecido pela própria Graphisoft para uso não comercial. A partir do API, é possível para programadores gerar novas ferramentas ou complementos para o software ArchiCAD (AYRES, 2009; GRAPHISOFT, 2011). Além do Graphisoft API, também foi utilizada a linguagem Ruby, por seu gerenciamento automático de memória, mostrando-se mais flexível do que a linguagem $\mathrm{C}++$.

\section{Desenvolvimento}

As atividades do plano de trabalho obedeceram às seguintes etapas: 1. Estudo de caso; 2. Elaboração da gramática da forma das habitações autoconstruídas; 3. Parametrização dos requisitos sustentabilidade ambiental e teste do plug-in.

\section{Estudo de caso}

Após a definição do objeto de estudo, a pesquisa passa ao campo prático, sendo guiada por um arranjo metodológico que envolvia a junção de diversos procedimentos aplicados em três etapas, dos quais incluíam leituras espaciais, levantamentos físicos e entrevista com os moradores. O objetivo dessa etapa foi colher informações que falassem da forma e do processo de formação das moradias desde sua implantação em 1990.

Diante da grande quantidade de unidades habitacionais na comunidade, foram elaborados critérios de seleção progressiva em cada etapa da pesquisa, os quais se referiam ao processo progressivo de produção da casa.

Inicialmente foi concedido aos pesquisadores o acesso a um cadastro de famílias na associação de moradores, onde constavam informações referentes aos dados pessoais, dados da moradia e da infraestrutura, os quais potencializaram a leitura espacial, que se deu na escala urbana. $\mathrm{Na}$ leitura espacial foram identificados o número de 
pavimentos das unidades, o número de unidades habitacionais em cada lote e o tipo de uso, a existência de recuos e sacadas e o registro dos acabamentos externos.

A segunda etapa da coleta teve como foco a unidade habitacional. Os procedimentos investigativos aplicados foram o levantamento físico da unidade e a aplicação de um formulário com perguntas acerca do processo de construção da moradia. Essa etapa foi responsável pela geração de grande quantidade de dados que foram tabulados para orientar a aplicação das atividades subsequentes.

Dando prosseguimento, a última etapa foi aplicada em unidades cujas informações coletadas na etapa anterior confirmassem progressividade na construção da moradia, identificadas a partir da comparação entre as condições iniciais de instalação e a morfologia atual das unidades. Essas variáveis foram identificadas a partir dos dados dos formulários e do estudo das plantas baixas das unidades.

Concluído o planejamento, deu-se início à coleta prevista para a última etapa, que constava de entrevista narrativa. $\mathrm{Na}$ aplicação dos procedimentos foi utilizado um gravador de áudio, um formulário guia para a entrevista e a planta baixa das unidades visitadas.

Inicialmente era solicitada a permissão para gravar a conversa e então era solicitado ao entrevistado que reconstituísse a história de sua casa, apresentando os passos dados em cada etapa de construção, os cômodos que iam sendo construídos ou modificados e os motivos que determinavam cada ampliação.

Findada a coleta, deu-se início à transcrição e ao redesenho da moradia, de acordo com o processo progressivo de construção informado nas narrativas. A catalogação e análise de todos os dados (plantas e entrevistas) ocorreram seguindo as indicações de Bardin (1977), referentes à análise qualitativa de conteúdo.

\section{Elaboração da gramática da forma das habitações autoconstruídas}

A gramática da forma foi gerada a partir da análise descritiva dos dados coletados em campo. O material coletado para essa análise compreendeu uma amostra de 94 plantas baixas das moradias, obtidas a partir de levantamento físico.

Com a organização das análises, muito se pôde conhecer sobre as moradias autoconstruídas, sobre seu processo de formação, sobre o tipo arquitetônico. Assim, através da exploração morfológica com a identificação das recorrências e de singularidades, revela-se o tipo.

As análises foram realizadas em três distintas dimensões:
(a) a casa no lote;
(b) a casa em suas partes; $\mathrm{e}$
(c) a progressividade na construção da moradia.

\section{A casa no lote}

Contemplou as análises das variáveis que definem o lote, tais como sua área, forma, proporção, testada, taxas e formas de ocupação e áreas livres. Essas análises nos permitiram compreender as possibilidades de expansão das unidades.

Em resumo, identificaram-se como características morfológicas: testada $(\mathrm{Ft})$ entre $3,5 \mathrm{~m}$ e $4,5 \mathrm{~m}$, relação entre a lateral e a frente $(\mathrm{Lt} / \mathrm{Ft})$ de 3 a 4 , áreas de $50 \mathrm{~m}^{2}$ a $70 \mathrm{~m}^{2}$, com espaço livre (Lv) situado no fundo do lote e taxa de ocupação superior a $85 \%$. A Figura 2 ilustra o terreno em suas partes e forma de ocupação.

\section{A casa em suas partes}

Caracterizou o zoneamento e a compartimentação, no que se refere aos usos destinados aos espaços, áreas, proporções e relações espaciais. Ressalta-se que a estrutura funcional da moradia se altera conforme a unidade cresce, sendo abrigadas novas funções nos espaços preexistentes.

O zoneamento e a compartimentação das unidades foram classificados em zona de servir e zona servida, que por sua vez se desmembra em zona de estar e zona de dormir, de acordo com o Quadro 2. Destaca-se que muitos ambientes se apresentam com funções múltiplas, ou seja, há casos em que um mesmo espaço é utilizado para preparo + refeição ou estar + descanso. Nesses casos buscouse identificar a atividade predominante.

Antes de se iniciar a verticalização da unidade, o zoneamento no pavimento térreo ocorre de forma semelhante na maioria das unidades, excetuandose os lotes com proporções diferentes do padrão encontrado. A Figura 3 representa $84,6 \%$ das unidades térreas levantadas, e foi observado que em $87,4 \%$ destes a subdivisão ocorre conforme a forma (a) e em 12,6\% de acordo com a forma (b).

A partir da observação visual das unidades, notouse uma relação de proporção entre as divisões dos compartimentos no sentido da profundidade. Assim, surge a percepção de que há uma modulação na divisão longitudinal do lote. Portanto, para a definição dos parâmetros dimensionais foi proposta uma divisão da lateral 
de todas as unidades em 12 partes iguais, de modo a identificar a proporção entre as zonas, conforme ilustrado na Figura 4, que representa a mancha ocupada por cada setor.

Pode-se notar que a zona de servir varia entre 3 e 7 módulos (3X a $7 \mathrm{X})$ e a zona servida oscila entre 5 e 9 módulos (5X a 9X). As análises dos arranjos de ambientes de cada zona contemplaram a listagem de cada espaço, a observação das suas proporções e a relação espacial entre os cômodos. A Figura 5 exemplifica a subdivisão da zona de estar e as propriedades dimensionais dos ambientes (Tabela $1)$.

Figura 2 - Lote e distribuição da ocupação

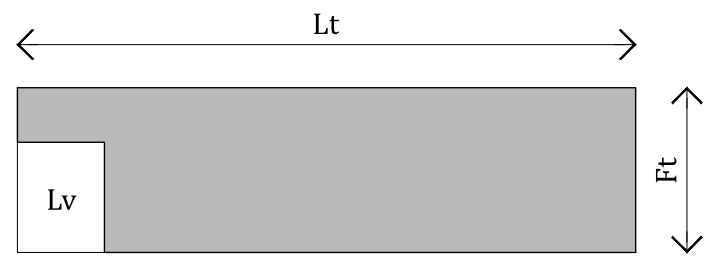

Quadro 2 - Zoneamento e classificação dos ambientes por seus usos

\begin{tabular}{|l|c|l|c|}
\hline Zona funcional & Símbolo & \multicolumn{1}{c|}{ Ambientes } & Símbolo \\
\hline Zona de servir & Zs & Refeição & $\mathrm{r}$ \\
\hline & & Lavanderia & $\mathrm{l}$ \\
\hline & & Depósito & $\mathrm{d}$ \\
\hline & & Banheiro & $\mathrm{b}$ \\
\hline & & Área livre de fundo & Lv.Fd \\
\hline & Ze & Espaço de transição & et \\
\hline & & Varanda & $\mathrm{v}$ \\
\hline & & Sacada & $\mathrm{sc}$ \\
\hline & & Garagem & $\mathrm{g}$ \\
\hline & & Sala de estar & $\mathrm{s}$ \\
\hline Zona de dormir & Zd & Área livre de frente & Lv.Ft \\
\hline & & Buarto & $\mathrm{q}$ \\
\hline Conexõeiro & & Circulação e escada & $\mathrm{c}$ \\
\hline Profissional & & Trabalho & $\mathrm{t}$ \\
\hline & & \multicolumn{2}{|c}{} \\
\hline
\end{tabular}

Figura 3 - Distribuição do zoneamento funcional das UHs térreas

(a)

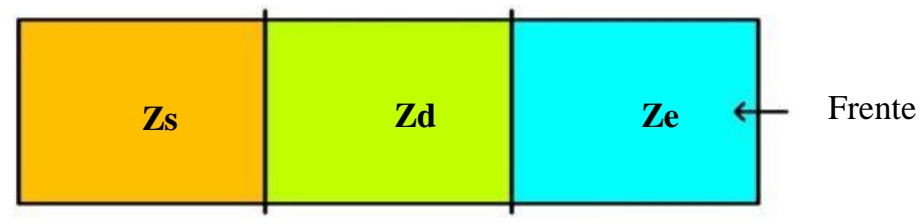

(b)

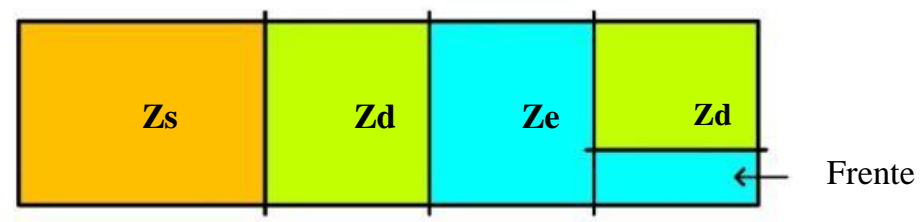


Figura 4 - Exemplo da divisão modular dos lotes com unidades térreas e mancha dos setores
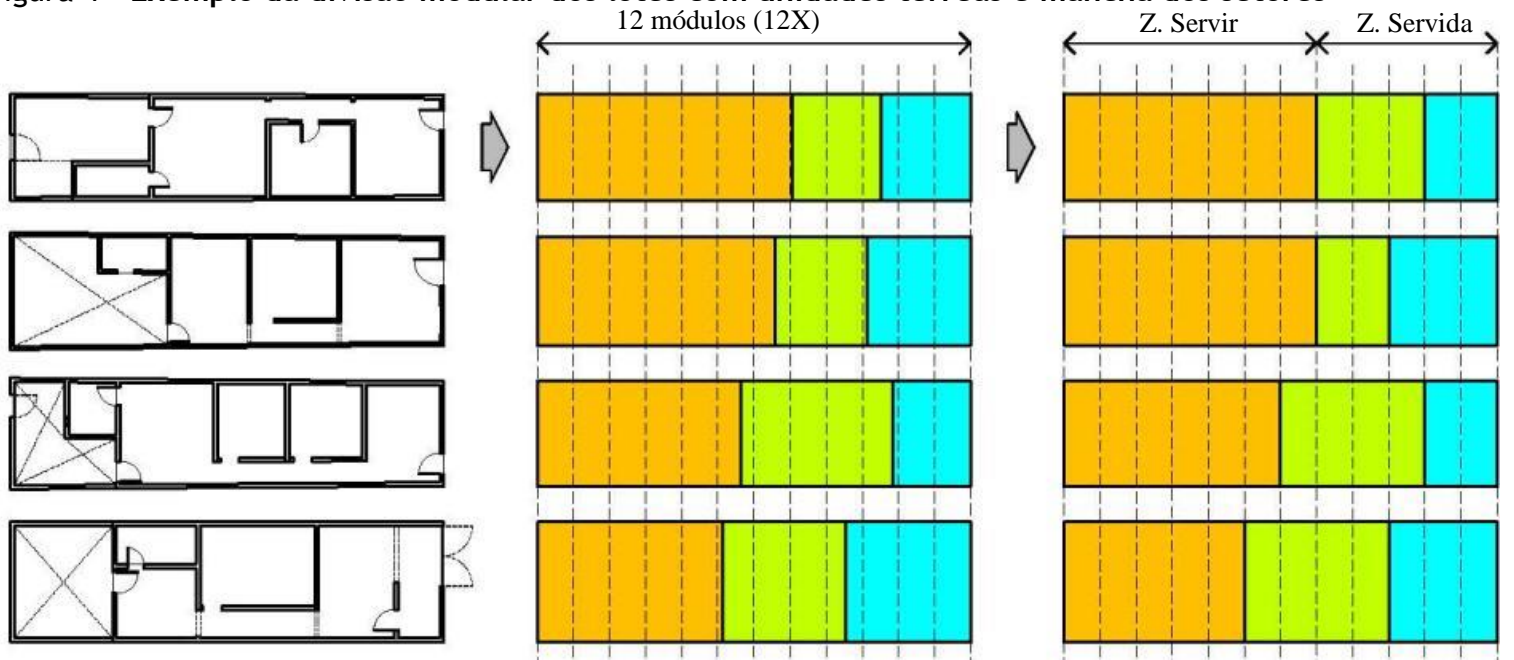

Figura 5 - Estrutura funcional da zona de estar (Ze). Arranjos: (a) sala; (b) sala + espaço de transição; (c) sala + área livre de frente; (d) sala + garagem

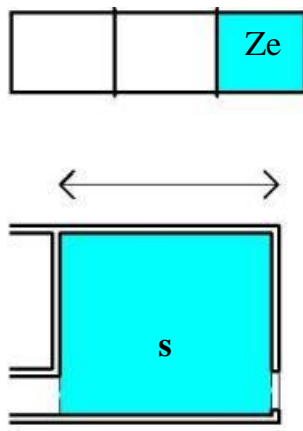

(a)

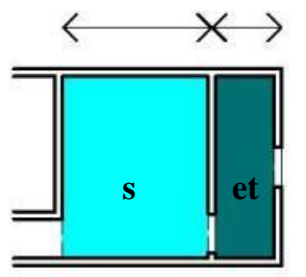

(b)

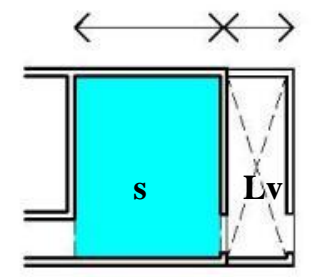

(c)

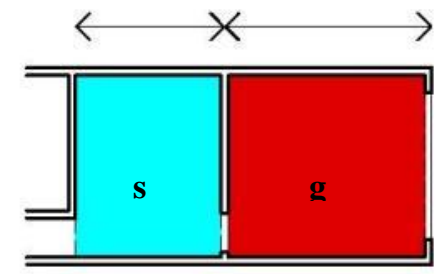

(d)

Tabela 1 - Dimensões dos cômodos da zona de estar (Ze)

\begin{tabular}{l|l|l|l|l|l|l|l|l|}
\hline & \multicolumn{3}{|c|}{ Área $\left(\mathbf{m}^{2}\right)$} & \multicolumn{2}{c|}{ Menor dim. do cômodo (m) } & \multicolumn{2}{l}{ Modulação $\longleftrightarrow$} \\
\hline & mín & máx & moda & mín & máx & Moda & mín & máx \\
\hline Sala de estar (s) & 5,9 & 17 & 10,0 a 13,0 & 1,4 & 3,8 & 2,5 a 3,5 & $2 \mathrm{X}$ & $3 \mathrm{X}$ \\
E. transição (et) & 2,6 & 11 & 4,0 a 7,0 & 0,9 & 2,9 & 1,0 a 1,5 & $1 \mathrm{X}$ & $2 \mathrm{X}$ \\
Área livre (Lv) & 2,2 & 8,2 & 5,0 a 6,0 & 0,8 & 2,1 & 1,0 a 1,5 & $1 \mathrm{X}$ & $2 \mathrm{X}$ \\
Garagem (g) & 9,5 & 17 & 12,0 a 15,0 & 2 & 3,7 & 3,0 (x 4,3) & $3 \mathrm{X}$ & \\
\hline
\end{tabular}

As regras da gramática foram definidas a partir da subdivisão do lote em partes que correspondem aos setores e aos compartimentos, considerando as dimensões modulares mais recorrentes. Assim, as dimensões dos espaços podem receber tamanhos diferentes dentro da faixa modular e dos arranjos de cada setor. Desse modo, mesmo se referindo a formas recorrentes, a gramática representa a pluralidade das moradias, corroborando com os conceitos de tipo.

A gramática das unidades térreas foi composta de 16 regras correspondentes à criação do lote e sua subdivisão em setores e compartimentos, dentre as quais são apresentadas abaixo as regras R1 a R4.
Para a derivação de unidades em processo de verticalização foram elaboradas as regras de progressividade na construção, totalizando 32 regras.

\section{Parametrização dos requisitos de sustentabilidade e teste do plug-in}

Os dados coletados e analisados constituem um agrupamento do conhecimento produzido informalmente e de maneira compartilhada, e indicam a forma mais adequada de organizar a moradia dessa população. Entretanto, é indiscutível a necessidade de estudos complementares sobre as condições de conforto e

34 Mororó, M. S. de M.; Romcy, N. M. e S.; Cardoso, D. R.; Barros Neto, J. de P. 
salubridade, da mesma forma no que diz respeito aos padrões construtivos e legais como forma de promover moradias adequadas, considerando os modos de morar e os aspectos ambientais.

Como exemplo tem-se a zona de dormir, que se localiza predominantemente na faixa intermediária do lote, o que pode gerar problemas relativos à salubridade e ao conforto ambiental, visto que esses ambientes não possuem contato com o meio externo por se tratarem de unidades geminadas. Um paliativo adotado com frequência é a construção de paredes que se afastam do teto, conforme se verifica na Figura 7.

Essa solução, no entanto, pode gerar incômodos em relação à privacidade. Nesse caso, na ocasião da geração do projeto é proposta uma solução, como, por exemplo, a abertura externa e a inserção de recuo lateral.

\section{Figura 6 - Regras da gramática da forma. Regras R1 a R4}

Regra R1: definir lote

Insere a forma do lote de acordo com os parâmetros indicados e adiciona os marcadores.

O símbolo $\varnothing$ marca o início da derivação e representa a forma inicial.

Parâmetros: Ft x Lt: 50,0 m² a 70,0 m²; Ft: 3,5 m a 4,5 m; Lt/Ft: 3,0 a 4,5

Marcadores: Ft: frente do lote; Lt: lateral do lote; Fd: fundo do lote; T: indicativo de aplicação das regras no pav. térreo.

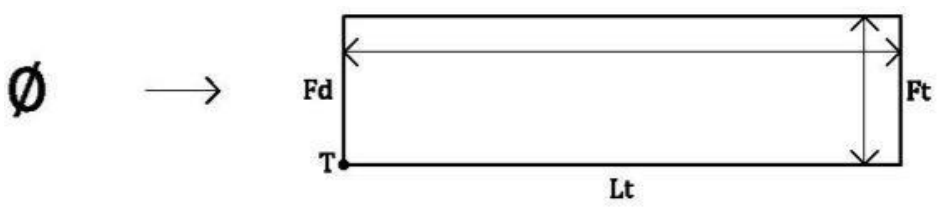

Regra R2: subdividir o lote em zona de servir e zona servida

Subdivide Lt de acordo com os parâmetros indicados e insere identificadores [A, B, C].

Parâmetros: AB: 3X a 7X; BC: 5X a 9X.

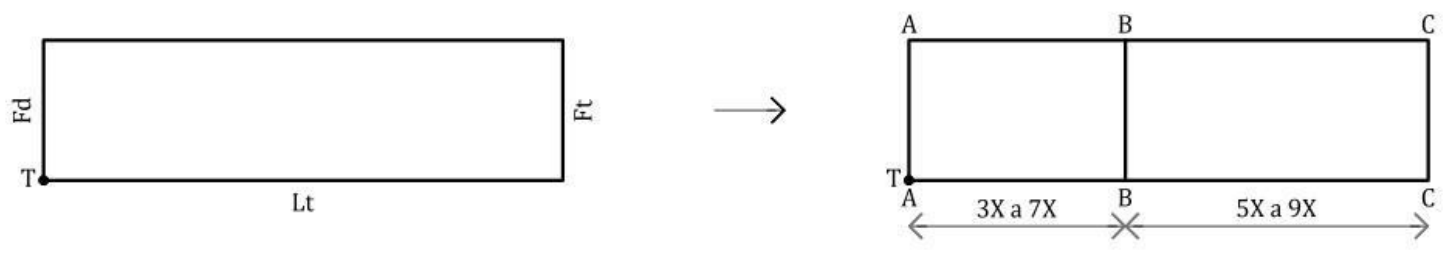

Regra R3: subdividir zona servida em zona de dormir e zona de estar

Subdivide o segmento BC de acordo com os parâmetros indicados e insere identificador [D].

Parâmetros: BD: 2X a 5X; DC: $2 \mathrm{X}$ a $5 \mathrm{X}$.
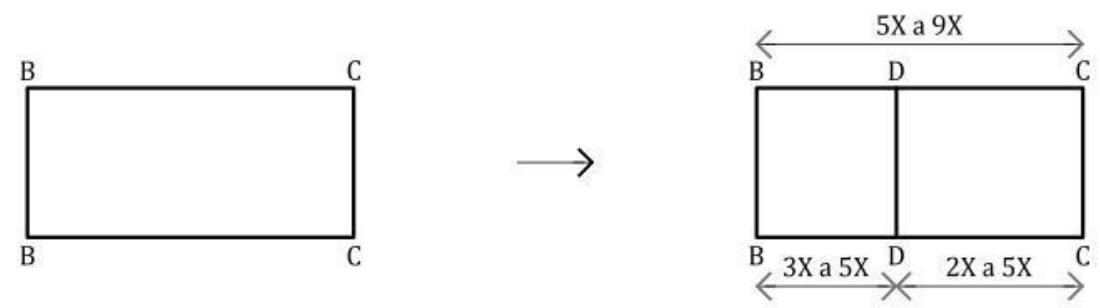

Regra R4: inserir circulação

Acrescenta uma subdivisão, no sentido paralelo a BD, a uma distância de $0,80 \mathrm{~m}$ de Lt entre as marcações verticais BB e DD e adiciona identificador [E].
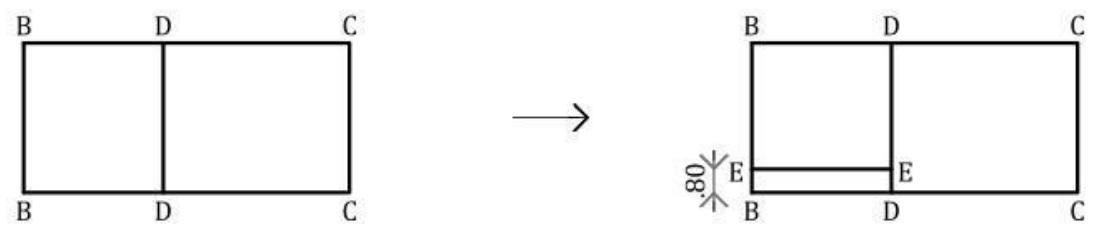
Figura 7 - Alvenaria divisória da zona de dormir

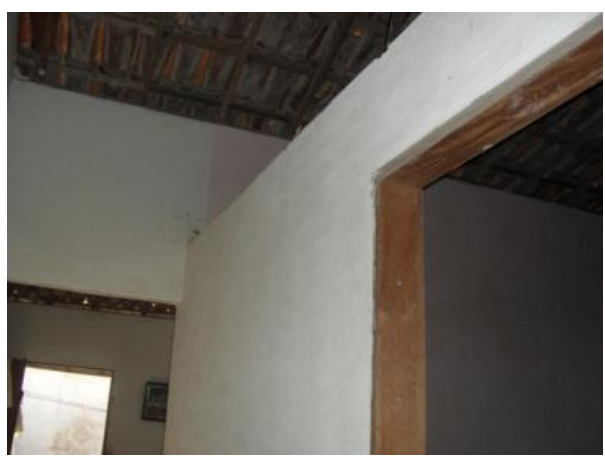

A partir da leitura e análise do Selo Casa Azul foram selecionados dez critérios (distribuídos entre as seis categorias do guia), por seu potencial de tradução em requisitos de projeto, e posterior parametrização. Desses critérios, buscou-se compreender os seus respectivos objetivos e em que fase do fluxo do processo de projeto eles deveriam ser considerados.

Os critérios selecionados foram:

(a) 1. paisagismo;

(b) 2. flexibilidade de projeto;

(c) 3. desempenho térmico - vedações;

(d) 4. desempenho térmico - orientação ao sol e ventos;

(e) 5. ventilação e iluminação natural de banheiros;

(f) 6. fontes alternativas de energia;

(g) 7. coordenação modular;

(h) 8. componentes industrializados ou préfabricados;

(i) 9; aproveitamento de águas pluviais; e

(j) 10. áreas permeáveis

Além dos critérios orientados pelo Selo Casa Azul, percebeu-se a necessidade de uma caracterização climática da cidade em que seria proposta a pesquisa. Para o conhecimento da realidade climática de Fortaleza, foram analisados dados climáticos disponibilizados pela estação meteorológica do Departamento de Engenharia Agrícola da Universidade Federal do Ceará, e posterior elaboração de gráficos de temperatura, umidade do ar, ventos e radiação solar. Por fim, foi elaborada a carta psicrométrica da cidade para definição das estratégias a serem utilizadas, a fim de melhorar as condições de conforto na elaboração de projetos.

Definidas as questões de sustentabilidade ambiental, passou-se à compreensão dos requisitos sociais a serem inseridos no processo. Esses

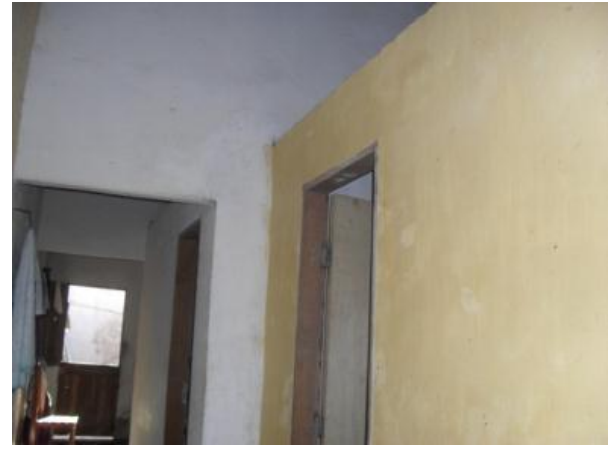

requisitos foram elaborados a partir das observações previamente descritas nas etapas de coleta de dados e gramática da forma, envolvendo as habitações autoconstruídas.

Determinadas restrições de projeto também foram resultantes da análise de legislação específica, como o Código de Obras da Prefeitura de Fortaleza (COPF) para casas e para Habitação de Interesse Social (COPF-HIS); o Plano Diretor Participativo do Município de Fortaleza (PDPFOR), que divide a cidade em Macrozonas de Ocupação Urbana e define os índices urbanísticos para cada área; e as especificações elaboradas pela Caixa Econômica Federal (CEF) para construção de casas do programa MCMV.

A análise dos levantamentos anteriores resultou nas seguintes informações a serem parametrizadas:

(a) 1. definição do lote;

(b) 2. área para a construção;

(c) 3. implantação e orientação;

(d) 4. compartimentação (identificação dos ambientes, suas posições e dimensões em relação à habitação, além da forma como eles se interrelacionam);

(e) 5. aberturas, dimensão e posição dos vãos;

(f) 6. proteções solares;

(g) 7. cobertura; e

(h) 8. materiais e revestimentos.

Essas características foram introduzidas nas etapas do fluxo de informações descrito durante o processo de projeto.

Para cada etapa foram definidos dados de entrada compostos de definições e informações iniciais, ou resultados da etapa anterior. Podem representar restrições (parâmetros condicionantes) ou limitantes para criação do objeto. Já os dados de saída, como o próprio nome indica, são as informações ou os desenhos gerados como resultado de uma etapa específica. 
Figura 8 - Fluxo de informações

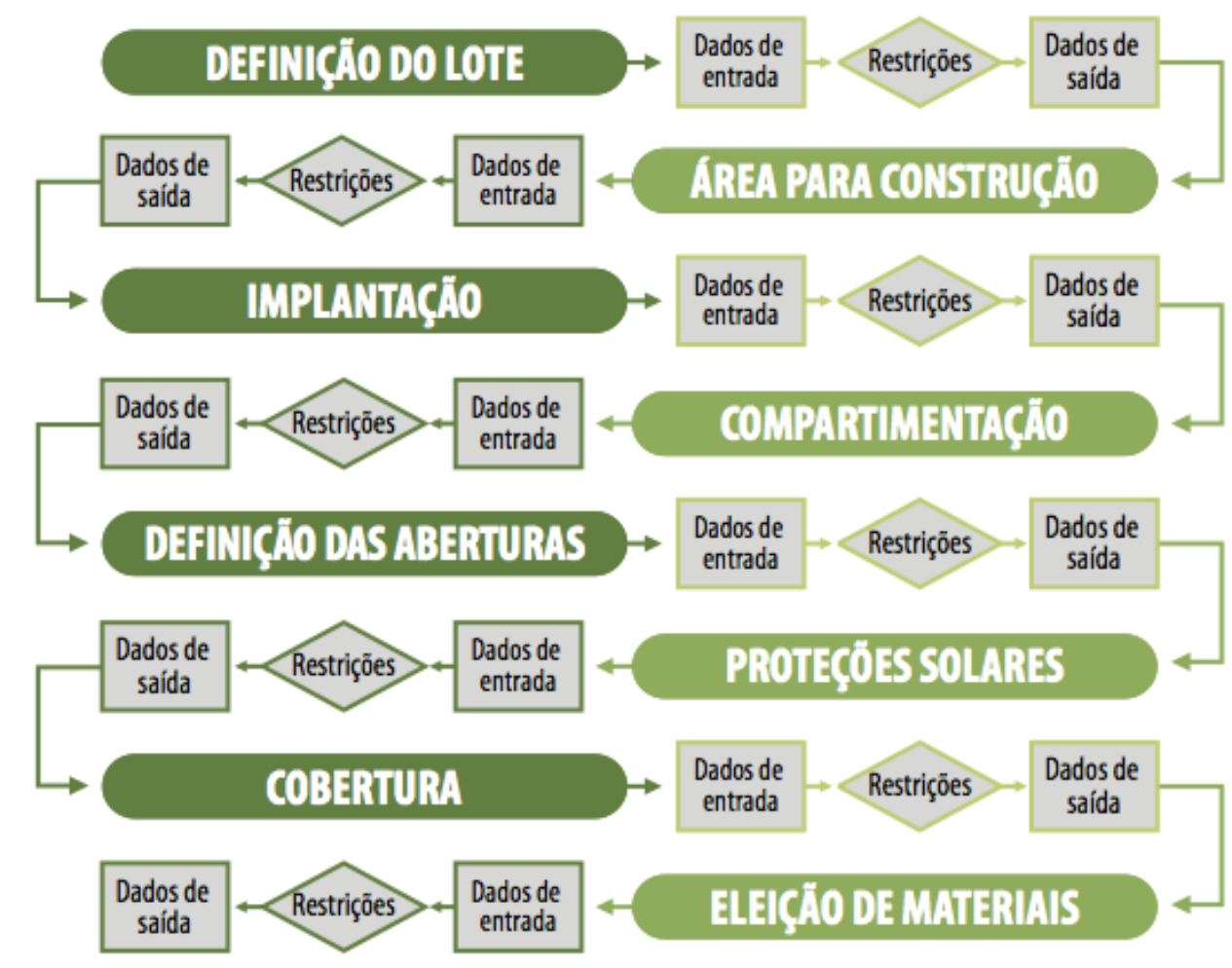

A partir dos resultados definidos no fluxo de informações, passou-se ao processo de customização dessas informações paramétricas para um ambiente BIM, que buscou o incremento de funcionalidades ao software ArchiCAD. Para isso, foi adicionada uma nova interface de iteração com o usuário, que possibilitou a entrada e verificação de dados de acordo com as restrições determinadas anteriormente, consolidados em um plug-in. Esses dados são usados para a geração dos projetos, seguindo as etapas desde a definição do lote até a etapa de eleição de materiais. A solução desenvolvida é um protótipo com o objetivo de validar o processo de elaboração de projetos e automatizar algumas etapas.

Quanto às tecnologias que foram utilizadas nessa etapa, o software ArchiCAD disponibiliza um Application Programming Interface (API), para que sejam desenvolvidos plug-ins. Esses são inicializados pelo software e complementam a sua interface gráfica. Para o desenvolvimento do plugin, foi utilizada a linguagem de programação $\mathrm{C}++$. E para o desenvolvimento da interface gráfica, foi utilizada a biblioteca Cocoa com a linguagem Objective- $C$ integradas ao código $\mathrm{C}++$.

Nas etapas de implantação, compartimentação, definição das aberturas e cobertura foi utilizada a linguagem Ruby, tomando como base a gramática da forma previamente sistematizada. Os dados de saída do código Ruby foram integrados com o código em C++ através do API do ArchiCAD, materializando o projeto a partir dos elementos característicos do software BIM (zonas, alvenarias, portas, janelas, coberta).

O plug-in utiliza uma variação de L-System para a geração das plantas. É um sistema parametrizado de reescrita em paralelo com um número fixo de iterações. Os parâmetros são: testada, comprimento, azimute e tipo do lote. Os valores dos parâmetros são definidos pela GUI do plug-in.

Quanto ao código, a definição da gramática pode ser visualizada no Quadro 3 ou no link: https://bitbucket.org/andrenpaes/gramatica/src/17d Of10ae7f55a496769248a384818e45329324b/Engi ne/gramatica.rb?fileviewer=file-view-default.

Quando executada, a gramática define os ambientes e suas dimensões e os organiza em uma árvore. Essa árvore é utilizada para posicionar cada ambiente e criar a planta.

A tela inicial da ferramenta é composta das seguintes entradas: zoneamento; testada; comprimento; e azimute. Também é composta de um quadro de mensagens no canto inferior esquerdo e de um quadro no lado direito que apresenta o resultado gráfico do lote, como apresentado na Figura 9. 


\section{Quadro 3 - Código de definição da gramática}

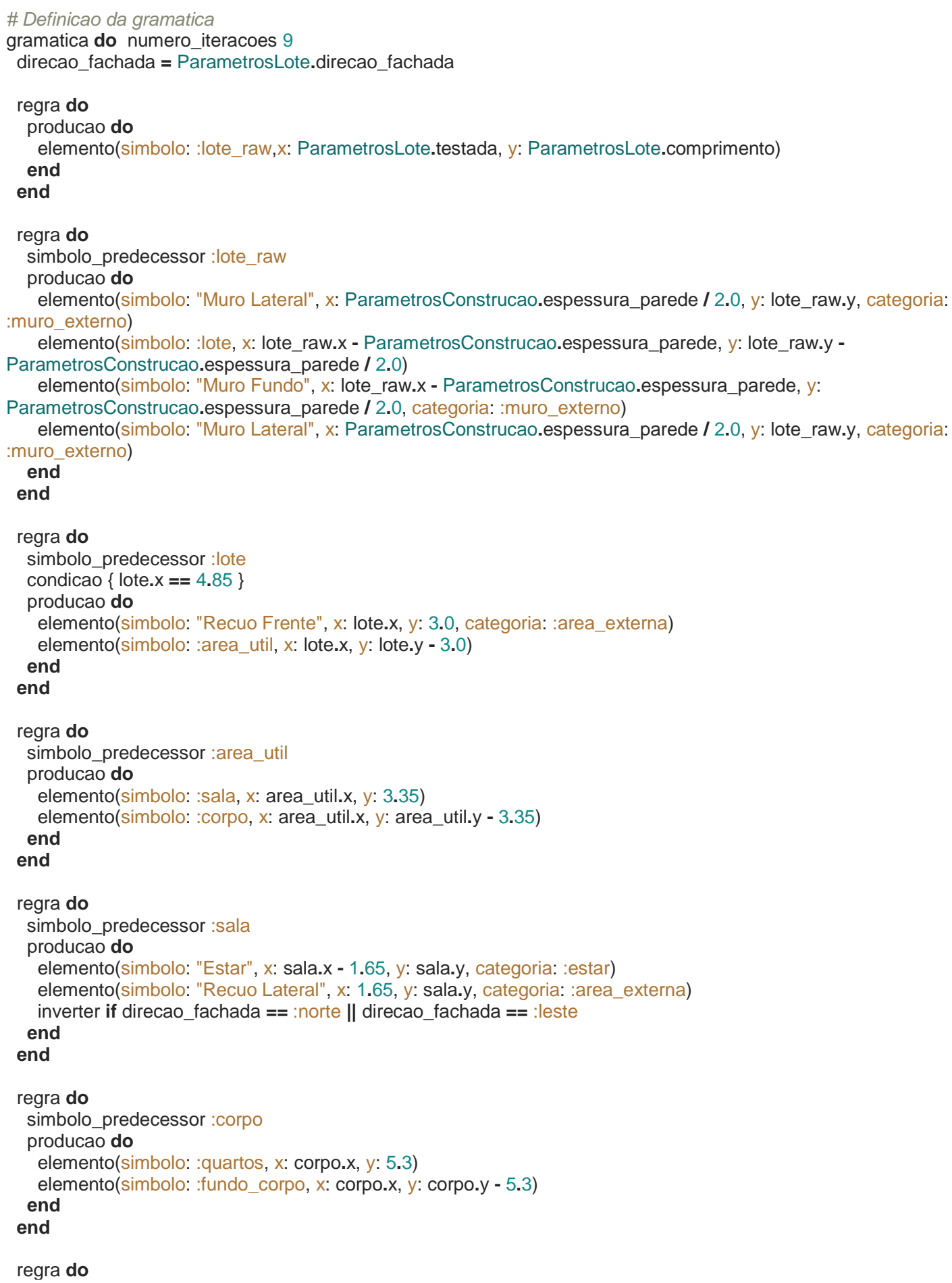




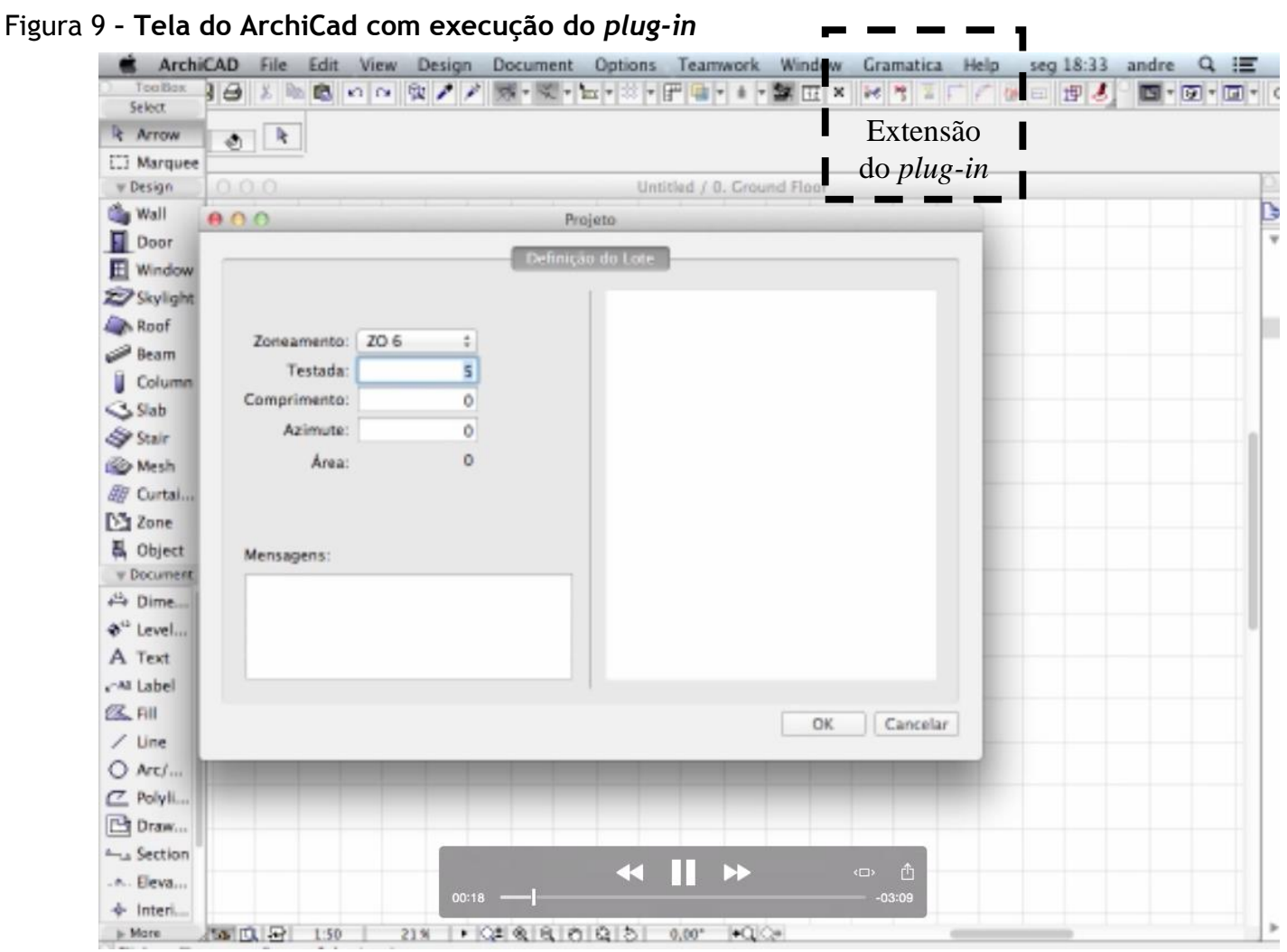

Como forma de testar a ferramenta foram realizadas diversas simulações. Para demonstração dos resultados capturou-se as imagens referentes a algumas etapas. Aqui apresentamos a geração de uma planta baixa da fase de definição do lote até a etapa das aberturas. Um vídeo apresentando o processo pode ser acessado no link: https://www.dropbox.com/s/tfux8nuzs7py9qk/Apr esenta\%C3\%A7\%C3\%A3o_Plug-in.mp4?dl=0.

O processo inicia com definição do lote, no qual foi simulado um terreno com medidas de $5,0 \mathrm{~m}$ de testada e 20,0 m de comprimento (Figura 10).

Como forma de comprovar as funcionalidades das restrições, foi inserida uma dimensão menor que a permitida no comprimento do terreno. Dessa forma, na porção inferior esquerda da tela surge uma mensagem indicando que o comprimento não deverá ser menor que $25,0 \mathrm{~m}$, e a área mínima do terreno é de $125 \mathrm{~m}^{2}$. Após a correção na entrada do dado deu-se prosseguimento às demais etapas (Figura 11).

Na sequência do processo, é necessário definir a Macrozona de Ocupação Urbana (PDDU-For) para que a ferramenta reconheça as restrições legais imposta para a área da cidade em que o terreno se localiza. Indica-se também o azimute do terreno para definição da orientação da fachada principal, conforme ilustrado na Figura 12.

Findada as definições do lote, o plug-in está configurado para geração de plantas baixas, com opções de projetos a serem selecionados. A Figura 13 apresenta a opção escolhida. 
Figura 10 - Tela com apresentação da restrição

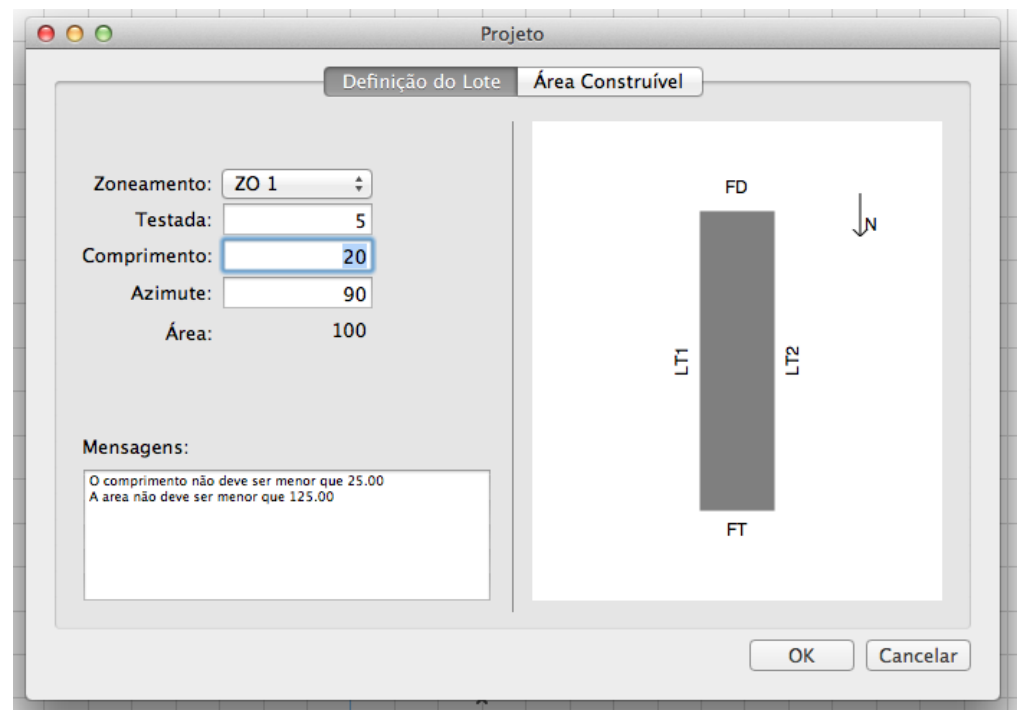

Figura 11 - Tela com o resultado da etapa de definição do lote

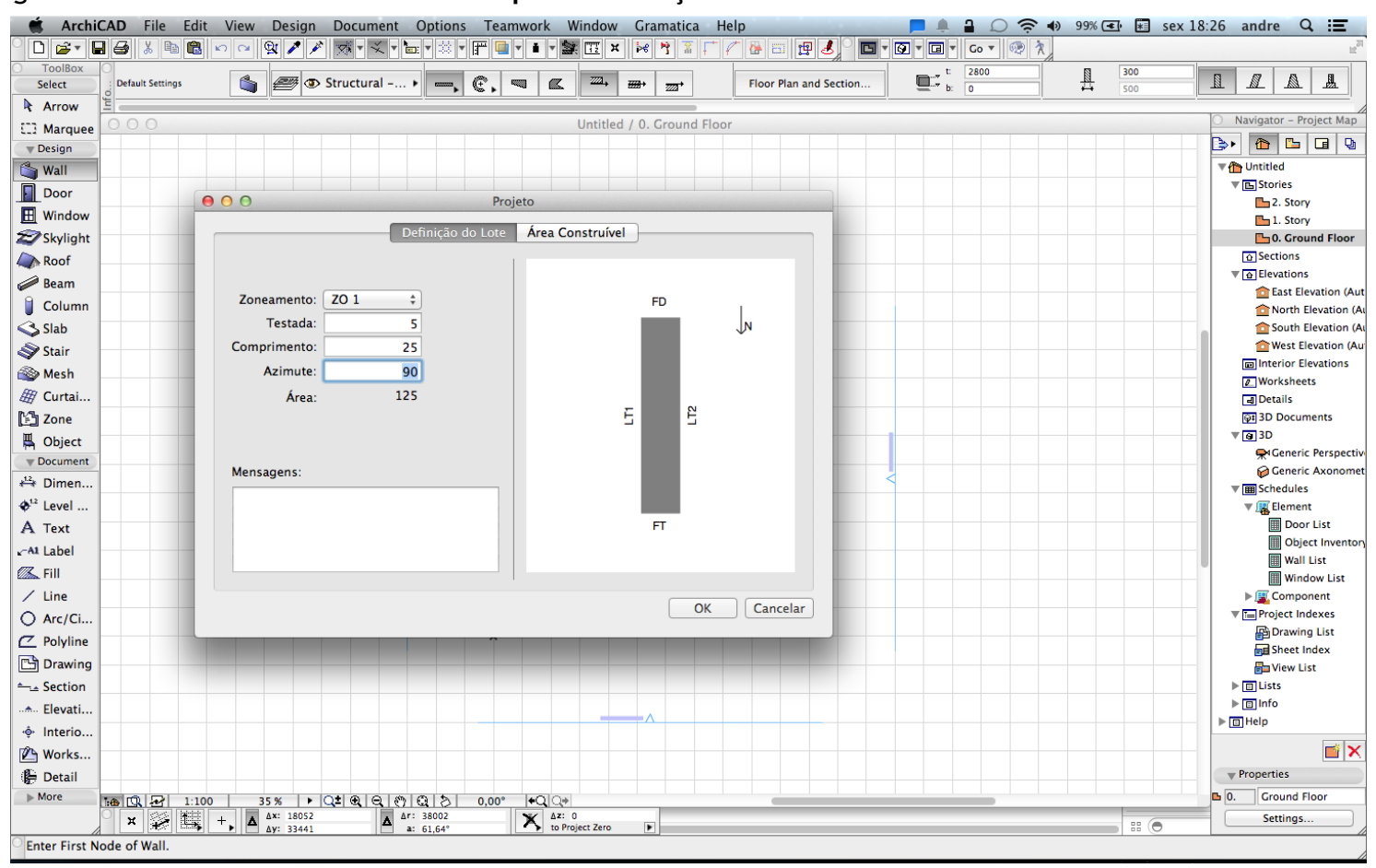


Figura 12 - Tela com a definição da Macrozona e do azimute da fachada do terreno

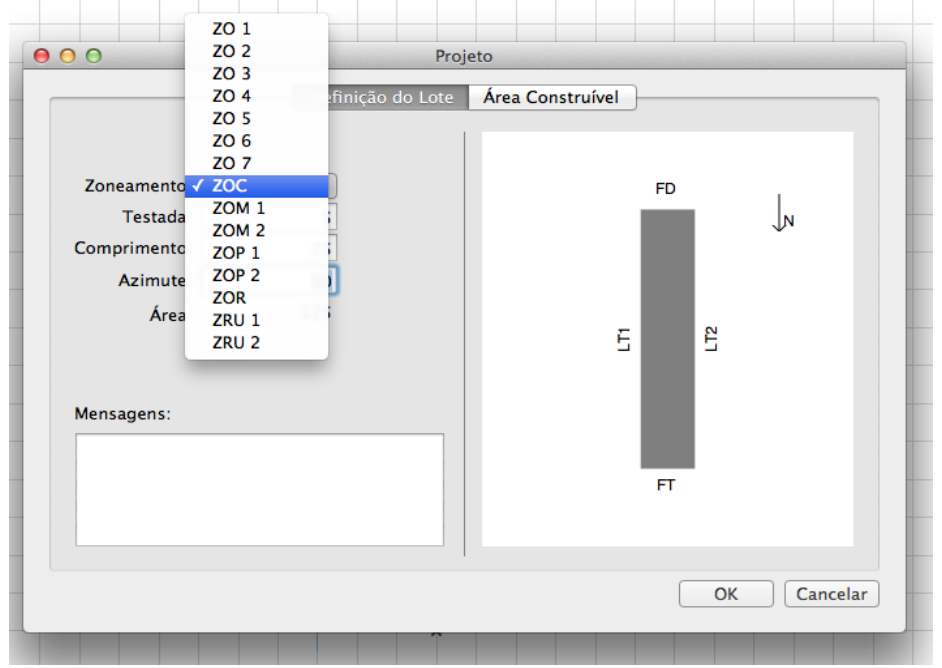

Figura 13 - Opção de planta baixa

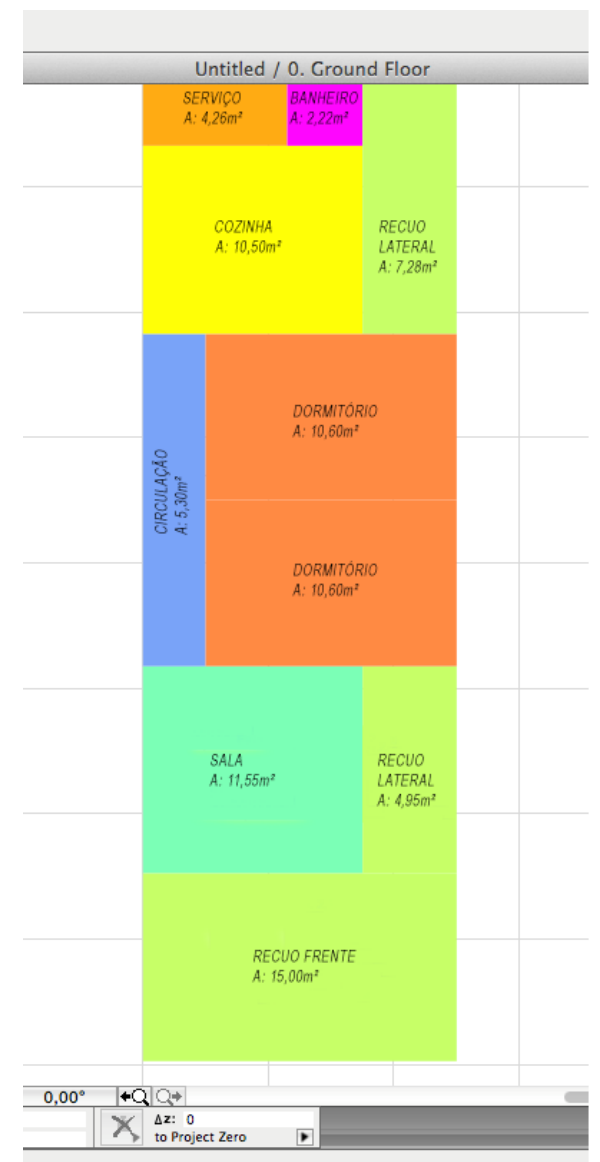

Inicialmente, o software apresenta uma planta baixa sem paredes, somente com a indicação dos ambientes em objetos Zona do ArchiCad e o selo com os dados de cada ambiente. Cada opção de projeto possui os cômodos com suas respectivas áreas e dimensões, seguindo os padrões máximos e mínimos e as relações espaciais definidas na gramática da forma. Definida a compartimentação da habitação e as relações entre os cômodos, partiu-se para a etapa de inserção das paredes e das aberturas, conforme a Figura 14.

Elevadas todas as paredes da habitação e definidas as dimensões das janelas e portas de cada ambiente seguindo os padrões definidos no desenvolvimento 
do fluxo de informações, o modelo está preparado para executar as entradas referentes às demais etapas de geração. Como exemplo, apresenta-se na Figura 15 a perspectiva da unidade definida até essa etapa.

\section{Considerações finais}

Das características estudadas sobre a moradia espontânea, a autoconstrução progressiva se mostra como o processo mais evidente, sendo esta a junção de esforços coletivos que acabam por definir os elementos formais das habitações, fruto do compartilhamento de conhecimento entre os autoconstrutores.

As evidências encontradas apontam para estudos sobre tipo como um elemento emergente dos processos citados. Os estudos indicam uma relação direta entre a forma da moradia e o contexto em que ela se insere. Considera-se que o tipo tem a propriedade de carregar a forma mais adequada de moradia para a população em questão e sua codificação representa uma forma de guardar os conhecimentos adquiridos sobre um grupo específico de indivíduos.

\section{Figura 14 - Planta baixa com paredes e aberturas}

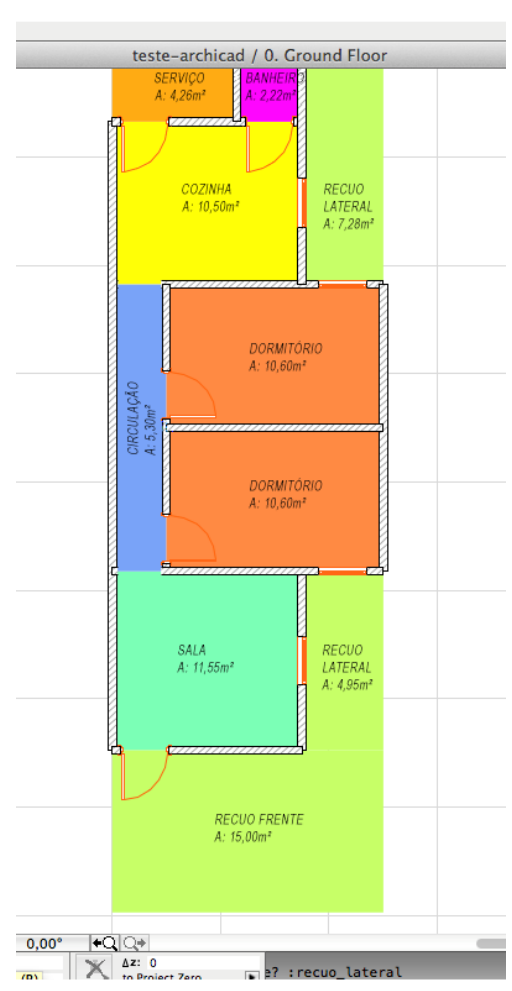

Figura 15 - Perspectiva da unidade elaborada até a fase de aberturas

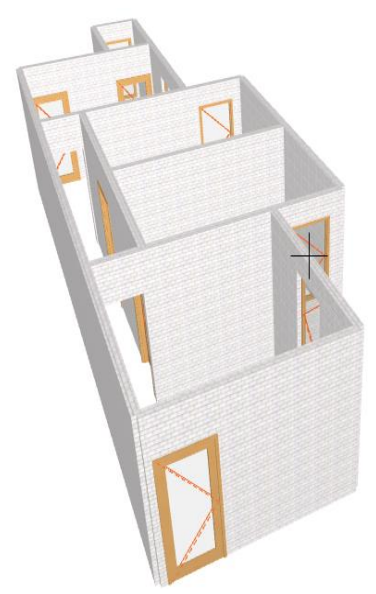

42 Mororó, M. S. de M.; Romcy, N. M. e S.; Cardoso, D. R.; Barros Neto, J. de P. 
Nesse contexto, esta pesquisa buscou reconhecer e codificar o modo de morar de parte da população desassistida das políticas públicas de promoção habitacional. Com os dados codificados em uma gramática da forma foi possível traçar os parâmetros encontrados e promover um ajuste de acordo com os critérios ambientais do Selo Casa Azul.

A sustentabilidade de uma edificação é algo complexo que não se resume a decisões e dispositivos técnicos somados ao projeto. Depende de uma abordagem bastante ampla dos problemas ambientais, econômicos e sociais, bem como de um compromisso ético ambiental e social de todos os atores envolvidos ao longo de todo o processo do empreendimento.

Nesta pesquisa, considerou-se os critérios sustentáveis sugeridos na certificação ambiental da CEF, que, por sua vez, são adequados quanto à realidade de habitações de interesse social. Para construção de um edifício sustentável, não precisam necessariamente ser utilizadas tecnologias inovadoras e metas para reduções drásticas de consumo, visto que podem tornar inviáveis economicamente esse tipo de habitação. No Selo Casa Azul, são sugeridas estratégias simples, tais como a racionalização do uso de materiais por meio do uso de pré-moldados e o desenvolvimento da coordenação modular.

Acredita-se que a sustentabilidade social foi alcançada no processo a partir do uso das informações coletadas nos levantamentos das habitações autoconstruídas. Não só as questões dimensionais dos ambientes, mas principalmente as características de relações entre os cômodos e sua disposição no terreno foram um diferencial na proposta de concepção de projeto.

$\mathrm{Na}$ elaboração de projetos de HIS, ressalta-se a importância de garantir flexibilidade na forma da habitação, dada a progressividade na construção da moradia. Assim, o projeto deve ser pensado de forma a possibilitar a ampliação de forma racional, implicando menores custos aos usuários.

A aplicação da pesquisa, com o desenvolvimento do plug-in, trouxe significativa contribuição tecnológica, o que possibilitou inovações no processo de concepção arquitetônica, no qual foi utilizada uma ferramenta BIM, consolidando os conhecimentos gerados nas etapas anteriores e agilizando o processo de elaboração do projeto com a automatização das etapas.

Os objetivos propostos por esse trabalho foram atingidos; contudo, as ferramentas desenvolvidas necessitam aperfeiçoamento em algumas áreas. Apesar das simulações realizadas para teste da ferramenta, é necessário o seu uso em situações do dia a dia.

Cada vez mais se desfaz a ideia de construir um modelo que atenda a todos. A personalização da habitação em série é uma estratégia para o aumento da satisfação e a redução de custos com reformas. Nesse sentido, o estudo indica uma metodologia de trabalho que deveria ser considerada no planejamento das moradias promovidas pelos programas habitacionais, salientando-se que os estudos prévios devem ser aplicados de forma particularizada para cada conjunto de famílias a serem atendidas.

\section{Referências}

ANDRADE, M. L. V. X.; RUSCHEL, R. C. BIM: conceitos, cenário das pesquisas publicadas no Brasil e tendências. In: SIMPÓSIO BRASILEIRO DE QUALIDADE DO PROJETO NO AMBIENTE CONSTRUÍDO, 1., São Paulo, 2009. Anais... São Carlos: Universidade de São Paulo, 2009.

AYRES, C. Acesso ao Modelo Integrado do Edifício. Curitiba, 2009, 149 f. Dissertação (Mestrado em Engenharia Civil) - Programa de Pós Graduação em Construção Civil, Universidade Federal do Paraná, Curitiba, 2009.

BARDIN, L. Análise de Conteúdo. Lisboa: Edições 70, 1977.

BONDUKI, N. G. Origens da Habitação Social no Brasil: arquitetura moderna, Lei do Inquilinato e difusão da Casa Própria. São Paulo: Estação Liberdade, 2004.

CARDOSO, D. R. Desenho de Uma poiesis. Fortaleza: Expressão Gráfica e Editora, 2011.

CELANI, G. et al. A Gramática da Forma Como Metodologia de Análise e Síntese em Arquitetura. Conexão, Caxias do Sul, v. 5, n. 10, jul./dez. 2006.

DUARTE, J. P. Personalizar a Habitação em Série: uma gramática discursiva para as casas da Malagueira do Siza. Lisboa: Fundação Calouste Gulbenkian e Fundação para a Ciência e Tecnologia, 2007.

FERREIRA, J. S. W. (Coord.). Produzir Casas ou Construir Cidades? Desafios para um novo Brasil urbano. Parâmetros de qualidade para a implementação de projetos habitacionais e urbanos. São Paulo: LABHAB; FUPAM, 2012.

GRAPHISOFT. Graphisoft API Development Kit Documentation. 2011. Disponível em: <http://www.graphisoft.com/support/developer/do cumentation/DocAPIDevKit.html>. Acesso em: abr. 2011. 
KRYGIEL, E.; NIES, B. Green BIM: successful sustainable design with building information modeling. Indiana: Wiley Publishing, Inc., 2008.

LUKKA, K. The Constructive Research Approach. In: OJALA, L.; HILMOLA, O-P. (Eds.). Case Study Research in Logistics. Publications of the Turku School of Economics and Business Administration, Series B1: 2003.

MARICATO, E. Metrópole, legislaçÃo e Desigualdade. Estudos Avançados, São Paulo, v. 17, n. 48, p. 151-166, 2003.

MARICATO, E. Brasil, Cidades: alternativas para a crise urbana. Petrópolis: Vozes, 2001.

\section{MARROQUIM. F. M. G. Avaliação Pós-}

Ocupação de Unidades Residenciais

Modificadas de Um Conjunto Habitacional em

Maceió-AL: flexibilidade, dimensionamento e funcionalidade dos ambientes. Alagoas, 2007. Dissertação (Mestrado em Engenharia Civil) Programa de Pós-Graduação em Arquitetura e Urbanismo, Universidade Federal de Alagoas, Alagoas, 2007.
MITCHELL, W. J. Beyond the Ivory Tower: constructing complexity in the digital age. Science Magazine, v. 303, n. 5663, mar. 2004.

MORAES. D. Metaprojeto: o design do design. São Paulo: Edgard Blucher, 2010.

ORCIUOLI, A. Projeto Assistido Por Computador: ontem, hoje, amanhã. Revista Arquitetura e Urbanismo. São Paulo: PINI, 2010. Ed. 197.

PEQUENO, L. R. B.; ROSA, S. V. O Programa Minha Casa Minha Vida na Região Metropolitana de Fortaleza-CE: análise dos arranjos institucionais. Cadernos Metrópole, São Paulo, v. 18, n. 35, p. 191-215, abr. 2016.

TASCHNER, S. P. Política Habitacional no Brasil: retrospectivas e perspectivas. Cadernos de Pesquisa do LAP: Revista de Estudos sobre Urbanismos, Arquitetura e Preservação, São Paulo, v. 21, set./out. 1997.

WOODBURY, R. Elements of Parametric Design. Abingdon: Routledge, 2010.

Mayra Soares de Mesquita Mororó

Curso de Arquitetura e Urbanismo, Centro de Ciências Tecnológicas | Universidade de Fortaleza | Av. Washington Soares, 1321, Edson Queiroz | Fortaleza - CE - Brasil | CEP 60811-905 | Tel.: 3477-3000 | E-mail: mayrasoares.arq@gmail.com

\title{
Neliza Maria e Silva Rimcy
}

Superintendencia de Infraestrutura | Universidade Federal do Ceará | Av. Mister Hull, s/n, Bloco IPDI, Pici | Fortaleza - CE - Brasil | CEP 60440-552 | Tel.: (85) 3366-9550 | E-mail: neliza.romcy@gmail.com

\section{Daniel Ribeiro Cardoso}

Programa de Pós-Graduação em Arquitetura e Urbanismo + Design | Universidade Federal do Ceará | Av. da Universidade, 2890, Campus do Benfica | Fortaleza - CE - Brasil | CEP 60020-180 | Tel.: (85) 3366-7490 | E-mail: danielcardoso@ufc.br

\section{José de Paula Barros Neto}

Departamento de Engenharia Estrutural e Construção Civil, Centro de Tecnologia | Universidade Federal do Ceará | Av. Mister Hull, s/n, Bloco 710, Pici | Fortaleza - CE - Brasil | CEP 60455-760 | Tel.: (85) 3366-9600 | E-mail: barrosneto@gmail.com

\author{
Revista Ambiente Construído \\ Associação Nacional de Tecnologia do Ambiente Construído \\ Av. Osvaldo Aranha, $99-3^{\circ}$ andar, Centro \\ Porto Alegre - RS - Brasil \\ CEP 90035-190 \\ Telefone: +55 (51) 3308-4084 \\ Fax: +55 (51) 3308-4054 \\ www.seer.ufrgs.br/ambienteconstruido \\ E-mail: ambienteconstruido@ufrgs.br
}

44 Mororó, M. S. de M.; Romcy, N. M. e S.; Cardoso, D. R.; Barros Neto, J. de P. 